\title{
REGIMES DE SABER/PODER NO DISCURSO SOBRE AVALIAÇÃO DA EXTENSÃO
}

\author{
Celso Kraemer ${ }^{1}$ \\ Jeice Campregher ${ }^{2}$ iD
}

\begin{abstract}
Resumo
Este artigo discute os regimes de saber/poder atuantes nos discursos de avaliação da Extensão Universitária. A base metodológica é a arqueologia e a genealogia de Foucault. O material da análise foi extraído de um formulário em que professores propunham projetos de Extensão, numa universidade de Santa Catarina. São excertos de discurso que permitem rica análise dos regimes de saber/poder atuantes na Extensão Universitária. Pergunta-se que mecanismos internos e externos regulam as respostas dadas por professores a um formulário institucional sobre avaliação do acadêmico de Extensão? Tem-se como objetivo analisar no discurso sobre avaliação do acadêmico de Extensão, os regimes de saber/poder que o tornam possível. A análise evidenciou: o lugar institucional regula o discurso; há assimetria entre os sujeitos institucionais; dispositivos do poder disciplinar atuam sobre a avaliação; ela implica formas de condução da conduta; o conceito de participação evidencia um deslocamento do regime disciplinar para o regime maleável de poder, chamado de controle.
\end{abstract}

Palavras-chave: Regime disciplinar; Regime de controle; Análise de Discurso; Avaliação da Extensão Universitária

\section{INTRODUÇÃO}

As sociedades contemporâneas se apresentam com faces plurais, características

\footnotetext{
${ }^{1}$ Doutor em Filosofia pela PUC/SP. Professor titular de Filosofia e Professor permanente do Mestrado em Educação da Universidade Regional de Blumenau - FURB/Blumenau. Endereço: Rua Siderópolis, 254, Ap. 501, Bairro Itoupava Norte, Blumenau/SC, Brasil - CEP: 89010971. Telefone: (47) 8854-6140. Endereço eletrônico: kraemer250@gmail.com.

${ }^{2}$ Mestre em Educação. Professora efetiva de Língua Portuguesa no Estado de SC, professora de graduação (presencial e EAD). Endereço: Rua Bernardo Reich, n. ${ }^{\circ}$ 52, Itoupava Norte, Blumenau/SC, Brasil. Telefone: (47) 9153-6454. Endereço eletrônico: professorajeice@gmail.com
} 
KRAEMER, C.; CAMPREGHER, J.

múltiplas, velocidades sempre mais aceleradas. Neste contexto, é frequente termos a sensação de que somos incapazes de gerir nossa vida com razoável controle para assegurarmos a paz pessoal e social. Vendo por certa perspectiva, o poder e a violência têm crescido assustadoramente em nossos contextos.

Contudo, se analisarmos por outras perspectivas, poderemos observar que a sensibilidade social e moral para com a violência cresceu mais que a própria violência. Esta, por sua vez, mudou sua feição. Uma parte dela ocorre no universo das relações simbólicas. Outra parte ocorre no interior de nossas instituições, amarrando nossas subjetividades aos princípios de regulação social, disciplinar e de controle.

O presente artigo - a partir de uma temática bem específica -, interessa-se por discutir formas de poder que se desenvolvem no interior de nossas instituições sociais, bem como, os efeitos de sujeição que promovem. O objetivo é analisar o discurso acerca da avaliação do acadêmico de Extensão e, a partir disso, responder à pergunta: que mecanismos internos e externos regulam as avaliações registradas pelos professores no formulário institucional?

Os discursos para análise foram coletados em uma universidade pública de Santa Catarina, mantida pelas mensalidades pagas pelos alunos. Mais precisamente, advém de um processo avaliativo pelo qual passam programas/projetos de Extensão. Um formulário preenchido por proponentes: professores $^{3}$ e servidores interessados em desenvolver programas/projetos de Extensão sob reconhecimento e apoio da instituição.

\subsection{A pesquisa e o contexto - delineamentos}

Para compreender o que é ser bolsista/acadêmico de Extensão na instituição investigada, salienta-se que ela segue orientações de documentos do Fórum de Pró-Reitores de Extensão das Universidades Públicas Brasileiras. Neles,programas constituem-se por um “conjunto articulado de projetos e outras ações de extensão"(COORDENAÇÃO NACIONAL DOFORPROEX, 2007, p. 35).Na instituição pesquisada, cada projeto de extensão deve vincular-se a um programa de extensão. Por isso utilizamos programa/projetos.

$\mathrm{Na}$ instituição, os programas/projetos de Extensão são desenvolvidos por docentes e servidores técnico administrativos (proponentes), partindo de alguma necessidade detectada. Tais programas/projetos passam por processos seletivos, sendo ou não aprovados. Uma vez aprovados, recebem auxílio e bolsistas - alunos de graduação da instituição. Apesar da

\footnotetext{
${ }^{3}$ Durante a seleção de dados, selecionamos um padrão: projetos escritos apenas por docentes. 
REGIMES DE SABER/PODER NO DISCURSO SOBRE AVALIAÇÃO DA EXTENSÃO

diferença conceitual entre bolsista e acadêmico, os documentos da instituição às vezes utilizam o conceito de bolsista de extensão, em outros o conceito de acadêmico de extensão. Entende-se que todo bolsista é acadêmico e, por estar na extensão, é bolsista.As bolsas nos programas/projetos de Extensão constituem-se por auxílio financeiro, abatendo parte da mensalidade ou sacados em dinheiro. A instituição não interfere na seleção dos bolsistas, atribuição dos coordenadores, mediante os critérios. Os termos "bolsista", "acadêmico" e “aluno" de extensão são utilizados nos documentos da instituição.

Os projetos ou programas de Extensão são apresentados pelos proponentes - docentes e/ou servidores técnicos administrativos - em formulário próprio, da instituição. Nele há um item ( $\left.\mathrm{n}^{\circ} .14\right)$ que se refere ao aluno. Neste item o proponente deve registrar a formação propiciada ao acadêmico, o plano de leituras, de atividades e forma de avaliação desse acadêmico. Abaixo, o item 14.54:

14.5 Forma de acompanhamento e avaliação da participação do estudante, se necessário com a emissão de conceito final.

O item é quase idêntico ao documento do FORPROEX (2007).A avaliação do acadêmico segue diretivas do $\operatorname{FORPROEX(2007,~p.51).~Conceitualmente,~a~extensão~tem~sido~}$ objeto de discussões (BOTOMÉ, 1996;FREIRE, 1983; NOGUEIRA,2001; SOUSA, 2010). Quanto ao acadêmico que se envolve com extensão, há menos investigações (ARROYO, 2010; FERNANDES, 2008; SILVA, 2007; TOSCANO, 2006) $)^{5}$.

O graduando é colocado como ator fundamental da extensão. Para o FORPROEX(2007, p. 50 e 52) "um requisito para a existência das ações de extensão é o de envolver os estudantes, sua razão de ser [...] buscar este componente formativo, seja na perspectiva técnico-profissional e na de formação política, cidadã".

Para o Fórum nacional de extensão e ação comunitária das instituições de Ensino Superior Comunitárias (2005, p. 10-11) a extensão deve contribuir "para que os alunos desenvolvam no processo ensino-aprendizagem o espírito crítico próprio de uma formação ética e cidadã”. O aluno, portanto, é central na extensão universitária. Para Nogueira (2001, p. 59), esse direcionamento vem das ações da União Nacional dos Estudantes - principalmente de 60 a 64 -, que buscava levar "o estudante a participar da vida social das comunidades".

\footnotetext{
${ }^{4}$ Selecionamos apenas os formulários cujo item 14 estivesse inteiramente preenchido.

${ }^{5}$ Para ter acesso detalhado do Estado da Arte, consultar a dissertação de mestrado de CAMPREGHER, Jeice: O Dispositivo da cidadania e a avaliação do acadêmico na Extensão Universitária, disponível online na biblioteca universitária da FURB: $\underline{\text { bu.furb.br }}$
} 
KRAEMER, C.; CAMPREGHER, J.

\section{COMPONENTES FOUCAULTIANOS PARA A ANÁLISE DO DISCURSO}

Foucault desenvolve os conceitos da análise do discurso na arqueologia, embora ocorram também referencias conceituais na genealogia. Retomemos brevemente alguns de seus conceitos, como os da pergunta da pesquisa "mecanismos internos e externos" de regulação do discurso; procedimentos de exclusão de discurso. Para ele, há "procedimentos que têm por função [...] dominar seu acontecimento aleatório" (FOUCAULT, 2008a, p.8).

Não é algo externo ao discurso que o controla, "visto que são os discursos eles mesmos que exercem seu próprio controle" (FOUCAULT, 2008a, p. 21). Analisa-se o discurso em seu corpo, em sua materialidade: "os discursos 'se dizem' no decorrer dos dias e das trocas" (FOUCAULT, 2008a, p.22, grifos no original). Eles estão formulados em palavras e que se encontram disponíveis para usos dos sujeitos. O discurso está conectado às demais práticas e exercícios de poder, como se vê em Foucault (1999; 2000),em que centra sua análise na história da loucura, dos saberes, das ciências.Contudo, nas pesquisas posteriores, na genealogia (FOUCAULT, 1987; 1988) o saber está entramado com o poder, discutindo o eixo saber-poder-sujeito-verdade.

Aspecto importante na constituição de nossa sociedade, a disciplina, enquanto regime de poder, fez nascer a prisão, as oficinas, as escolas (FOUCAULT, 1987). As técnicas disciplinares objetivavam certo tipo de sujeitos: dar a ele um ofício, sendo dócil, útil, normal. A disciplina lança o olhar sobre o "um" e o diferencia, individualizando-o, um "objeto descritível e analisável" (FOUCAULT, 1987, p.158). Constante definição do fazer, no tempo e espaço, mediante exames. A avaliação põe em movimento estratégias de motivação ou coação. As condutas dos indivíduos, medidas pelos critérios de avaliação, permitem verificar se são seguidos ou não: produz-se "todo um saber individualizante" (FOUCAULT, 1987, p.104), nos relatórios, pareceres, fichas, etc.

Conforme Menezes (2008, p.30), a instituição escolar forma subjetividades, está "no nível daquelas que se servem das tecnologias e dos dispositivos de poder". Assim, a universidade é uma instituição na qual tecnologias e dispositivos de saber, de poder e de subjetividade são postos em funcionamento. Uma destas tecnologias é a disciplina, importante na análise e discussão dos dados, na medida em que ela serve de elemento de regulação dos discursos e das práticas.

A avaliação é também um efeito de poder para os que se inserem nos mecanismos institucionais, na posição de professor, de aluno, da sociedade abrangida pela Extensão. São posições e funções de poder nas relações, produzindo subjetividades e condutas. Costuma-se 


\section{REGIMES DE SABER/PODER NO DISCURSO SOBRE AVALIAÇÃO DA EXTENSÃO}

pensar no poder como alguém que o detém e o investe sobre outro (s). Contudo, ele captura os sujeitos para atingir certos resultados. Assumir uma posição de poder, docente, bolsista ou sociedade na Extensão, implica assumir um lugar de resultados, tanto na realidade quanto nas subjetividades.

Apesar de assumirem posições, não são esses sujeitos que produzem os critérios de avaliação. Estes vão ao encontro da norma (do normal/adequado/esperado), de critérios tacitamente estabelecidos, conhecidos e reconhecidos por diferentes espaços e mecanismos sociais e institucionais. A partir dessa normalidade e regularidade dos critérios, pode-se colocar em funcionamento a avaliação enquanto uma operação de ordenamento. Há uma operação de “aproximação, comparação e classificação [...] [que] parecem naturalmente necessárias" (VEIGA-NETO e LOPES, 2007, p.959).

Para Foucault, há algo que não se pode deixar de considerar ao se falar em exames ou em avaliações. Para o autor (1987, p.160), a avaliação ou o exame "está no centro dos processos que constituem o indivíduo como efeito e objeto de poder, como efeito e objeto de saber”. Processos formativos são potencializados por processos avaliativos.

Retornando à questão de assumir uma posição, para Foucault, há dois processos necessários e correspondentes: “[1] fixação dos papéis para os sujeitos que falam [...] [2] e uma apropriação do discurso com seus poderes e saberes" (FOUCAULT, 1987, p.44-45). Ao assumir uma posição discursiva, há poderes e saberes correspondentes. Dessa forma, assumir uma posição como a de docente, permite a esse sujeito pôr em jogo ou movimentar poderes e saberes - antes disso, são eles próprios atravessados pelo poder. Por isso a avaliação é entendida como um efeito de poder. Um efeito de poder produzido por esse assumir papéis: de sujeito do conhecimento (por parte do docente) e de ser conhecido e ser objeto de discurso (por parte dos discentes).

Exercerem o poder requer tornar-se sujeito de poder. Para Veiga-Neto e Traversini (2009, p.15) as pesquisas de Foucault que se interessam por governamento, de si e dos outros, têm como objetivo "descrever, examinar, analisar e problematizar outros modos pelos quais alguém se torna um sujeito". Consideramos que analisar processos avaliativos vai ao encontro dessa compreensão dos autores: a avaliação é um modo de tornar-se sujeito de poder, de colocar o poder em exercício - por parte dos que avaliam e dos que são avaliados. A avaliação como uma das ferramentas (no caso, disciplinar) de conduzir a própria conduta e a do outro. Pode-se entender que a Educação tem, em si, essa pretensão - ela tem por razão ou justificativa conduzir, levar, encaminhar os sujeitos para dentro de formas de existência desejadas. 
KRAEMER, C.; CAMPREGHER, J.

Os conceitos até aqui abordados servirão como ferramentas para analisar os excertos do discurso acerca da avaliação do acadêmico de Extensão. As discussões nos permitirão esboçar respostas à pergunta de partida: que mecanismos internos e externos regulam as respostas dadas por professores a um formulário institucional?

\section{AVALIAÇÃO DO ACADÊMICO DE EXTENSÃO}

Para a análise e discussão de alguns excertos retirados do subitem 14.5 de programas/projetos de Extensão (PE), transcrevemos os excertos nos quadros ${ }^{6}$ a seguir. Todos foram digitados, rigorosamente, de acordo com os originais.

PE1: O coordenador do projeto acompanhará as atividades desenvolvidas pelo bolsista diretamente, orientando-o sempre que necessário

PE2: Com a peça elaborada, encaminhará ao professor coordenador para correção. O professor corrigirá e se tiver mudanças, o aluno as efetuará

PE9: O trabalho do estudante é acompanhado de perto pela coordenadora do Projeto, que avalia seu desempenho no cumprimento das atividades, principalmente em relação aos requisitos exatidão e articulação de informações.

Nos três PEs acima, o foco está nas atividades: orientação das atividades (PE1), elaboração e correção das peças (PE2) e cumprimento das atividades, com exatidão e articulação das informações (PE9). Supervisão e correção da atividade, da técnica, há um jeito certo para ser feito; esse jeito certo quem conhece é o coordenador. Essa descrição vai ao encontro do que Foucault observou, principalmente, nas oficinas: aqui há uma avaliação/correção da técnica, o objeto a ser produzido (FOUCAULT, 1987).

Centrar a avaliação nas atividades e no resultado esperado reproduz, na Extensão, o modo como é pensada e praticada a avaliação nas práticas atuais em educação. A educação é atravessada, em todos seus níveis, modalidades e espaços pelo discurso e pela prática da avaliação. O modo de se pensar a educação está, internamente, condicionado pela avaliação. Há, portanto, uma regulação interna do discurso, na medida em que vai ao encontro de um modelo de educação produzido e desejado socialmente, vai, igualmente, ao encontro da racionalidade das sociedades contemporâneas, embora a regulação da ação pelo domínio técnico,a ser algo antigo no exercício da própria ação, já tenha sido observado por Foucault

\footnotetext{
${ }^{6} \mathrm{~A}$ escolha por manter os excertos em quadros foi feita pelo seguinte motivo: para que os dados não fossem confundidos com citações diretas longas.
} 
REGIMES DE SABER/PODER NO DISCURSO SOBRE AVALIAÇÃO DA EXTENSÃO

(1987) nas oficinas, a Contemporaneidade ainda necessita do adestramento do corpo através das técnicas disciplinares, bem como de destreza técnica.

A disciplina é voltada para o "um” (para o corpo específico de cada pessoa); porém, pela técnica da distribuição espacial, temporal e hierárquica, com exame, vigilância e controle contínuos, assegura-se de alcançar o todo, ordenando os corpos, dando a cada um deles uma função (ou funções) específica(s) na distribuição e no agir dos corpos no todo do corpo social. Atinge-se, simultaneamente, a todos e a cada um individualmente. Somente se consegue o controle do todo quando se controla cada um individualmente, mas o controle do indivíduo depende da ordenação do todo, da composição de forças que regula e faz funcionar o todo, da distribuição e controle hierárquicos, das sanções previstas para normalizar, mas também de um complexo sistema de quem, em qual lugar da hierarquia, identifica a violação à norma, quem pune o infrator, com quais meios, quais as penas a serem aplicadas, etc. Uma sala de aula é um exemplo deste exercício disciplinar de poder, em que todo um sistema de ordenação, normalização.

Por parte dos docentes que formularam os excertos acima, além da regulação interna que se impõe e faz funcionar o próprio discurso, há também aspectos externos que regulam o que é dito: um sujeito assume a posição de quem conhece. Nesse nível, interessa observarmos a presença do poder regulando o dito. Para Foucault, o poder nunca cai somente sobre o que será educado/disciplinado. Cai também - ou mais intensamente - sobre aquele que conduz o outro. Há uma responsabilização pelos resultados que serão produzidos no corpo e na conduta do sujeito conduzido.

Passemos a outros excertos:

PE7: A avaliação do desempenho do bolsista se dará pela assiduidade, pontualidade, iniciativa, qualidade do trabalho realizado, organização e civilidade.

PE2: mensalmente [a professora orientadora] encaminha [...] o relatório de atividades, especificando as atividades desenvolvidas, avaliação da assiduidade/pontualidade do aluno, bem como a ética profissional, a iniciativa no desempenho das atividades e a interação grupal

Nesses enunciados, o foco do discurso sobre avaliação da Extensão que antes (no PE1 e PE2) estava voltado para as atividades, agora está dirigido ao comportamento do acadêmico bolsista de Extensão. A avaliação, nesse discurso, visa regular, modular, normalizar e controlar a conduta do acadêmico. Uma avaliação que dirige seu olhar, antes voltado ao 
KRAEMER, C.; CAMPREGHER, J.

objeto, à atividade, ao fruto do trabalho da pessoa, neste outro excerto volta-se para a própria pessoa. Ela se torna o “objeto descritível e analisável” (FOUCAULT, 1987, p.158).

Segundo PE2, mensalmente o docente encaminhará o relatório. Ao que se constata nos demais formulários, essa não é uma exigência da instituição. É opção do docente enviar relatórios frequentes; a condição para planejar e efetivar o envio mensal de relatório não se encontra, originariamente, nem na instituição, nem no docente. A origem está na própria maneira disciplinar, de exercício do poder que, por meio da vigilância hierárquica, do controle contínuo e da sanção normalizadora, promove "todo um saber individualizante" (FOUCAULT, 1987, p.104); tanto sobre o docente que produz o relatório quanto os atores sociais com os quais se promove a Extensão.

Essa modalidade de avaliação/controle não é, inicialmente, uma característica da universidade, nem da Extensão ou do docente que propõe enviar mensalmente relatórios. Isso é uma característica do modelo disciplina de exercício de poder. O docente é atravessado e faz funcionar o poder, não sendo ele propriamente a fonte do poder avaliador.

Aparentemente, os critérios na escolha do tipo de avaliação que procederá sobre o acadêmico de Extensão são "dele". Contudo, ao analisar genealogicamente o sistema de relações de forças que faz funcionar o poder, se percebe que ele (docente) é apenas um pequeno componente de uma maquinaria disciplinar bem mais ampla, complexa e eficiente, que ultrapassa em muito a vontade singular de uma subjetividade; a subjetividade de um docente avaliador é, antes de tudo, o efeito do poder disciplinar. Há a regulação interna ao próprio discurso, mas há também os dispositivos de poder que, de fora, do âmbito social dessa maquinaria de poder, atuam sobre o discurso, fazendo com que ele adquira um sentido e uma eficácia - os critérios são socialmente aceitos, desejados.

Ainda, sobre aspectos externos de regulação do discurso e, quiçá, das práticas, elas transcendem amplamente a vontade pessoal dos sujeitos. Estas, conforme já comentado, são o efeito de um sistema complexo, historicamente construído, de relações de poder, de crenças socialmente partilhadas, de tecnologias tornadas quase invisíveis pela própria dinâmica do poder. A arqueologia e a genealogia de Foucault visam dar visibilidade e dizibilidade aos dispositivos discursivos e não discursivos que fazem funcionar o poder e produzem subjetividades.

Mesmo que se deva atentar para o que Foucault (1987) chamou de vigilância hierárquica - na qual um sujeito pode avaliar outro, sem que o "outro" possa, reciprocamente, avaliar tal sujeito, instaurando uma relação assimétrica -, a assimetria está calcada sobre a modalidade própria à relação professor-aluno, vinculada à ideia de detentor-receptor de 
REGIMES DE SABER/PODER NO DISCURSO SOBRE AVALIAÇÃO DA EXTENSÃO

conhecimento - quem tem conhecimento avalia, enquanto o outro (sem conhecimento) é objeto da avaliação.

A essência da pedagogia moderna é a crença em dois sujeitos específicos e indispensáveis: o que ensina/educa/sabe e o que aprende/é educado/não sabe. Essa característica da pedagogia moderna

[...] divide a inteligência em duas. Uma inteligência inferior e uma inteligência superior. A primeira registra as percepções ao acaso, retém, interpreta e repete empiricamente, no estreito círculo dos hábitos e das necessidades. É a inteligência da criancinha e do homem do povo. A segunda conhece as coisas por suas razões, procede por método, do simples ao complexo, da parte ao todo (RANCIÈRE, 2002, p. 24).

Segundo o autor, esse é um mito pedagógico que produz o embrutecimento da inteligência, num processo que, do ponto de vista do professor, "vai de seu saber à ignorância dos ignorantes" (RANCIÈRE, 2002, p. 25). Essa prática de educação é chamada por Paulo Freire (1987) de educação bancária, por pautar-se nos depósitos de conteúdos que o professor realiza sobre a cabeça dos alunos. A pedagogia dessa modernidade está centrada em uma "linguagem da aprendizagem" (BIESTA, 2013, p. 30) em que a educação é pensada como preparação de um porvir, "uma trajetória da infância para a vida adulta" (ibidem) em que a criança desenvolve um papel de passividade receptiva, a ser enchida ou completada pela pedagogia dos adultos.

Outro componente importante da pedagogia moderna é a noção de governo da conduta ou de condução da conduta. Essa é uma convicção que, segundo Foucault (2008b), tem sua origem mais antiga, pois ela se desenvolveu a partir do poder pastoral, modificando-o. No poder pastoral há uma relação pessoal, com exegese cotidiana das ações e das intenções, como se vê entre os estóicos latinos e na confissão do cristianismo. São exercícios de espiritualidade baseados na confiança mútua e amparada num trabalho sobre si, em que se governa a conduta do outro até esse poder conduzir-se a si próprio (FOUCAULT, 2008b). A pedagogia moderna, âmbito no qual se inscreve o discurso sobre avaliação do acadêmico/bolsista de Extensão dos excertos analisados nessa pesquisa, baseia-se na tecnologia disciplinar, impessoal, funcionando como máquina abstrata,

Não queremos enxergar nisso uma anomalia. As relações são comumente assimétricas, principalmente no meio educacional. Para Veiga-Neto (2006, p.21), tais relações de poder "visam a dominação do(s) outros(s) segundo uma racionalidade própria. O mesmo autor acrescenta: 
KRAEMER, C.; CAMPREGHER, J.

Não há nem mesmo como imaginar uma cultura, qualquer cultura, sem ações continuadas e minuciosas "daqueles que já estavam aí" sobre "aqueles que não estavam aí", de modo a incorporá-los aos códigos, saberes, crenças, práticas, representações, valores e tudo o mais que compõe uma cultura e que "já estava aí" (VEIGA-NETO, 2006, p. 30, aspas no original).

Apesar de os acadêmicos de Extensão não serem "recém-chegados" em determinada cultura (crianças), ainda assim, há saberes, crenças, práticas, os quais eles podem incorporar ao seu modo de vida - ainda há uma cultura, um modo de ser a incorporar: uma cultura acadêmica/extensionista, um modo de ser específico. Sempre há o que aprender com os que “já estavam aí. Em outras palavras, é com base na educabilidade, ou seja, com base no fato de o sujeito ser tomado como educável, que se pode colocar em ação a governamentalidade, a gestão das condutas (SILVA e FABRIS, 2010).

Em outros excertos se pode observar um mecanismo de classificação dos indivíduos através do processo avaliativo:

PE11: Todos os acadêmicos serão avaliados através de critérios pré-estabelecidos. Estes critérios contemplam responsabilidade, assiduidade, apresentação pessoal, habilidade técnica, iniciativa para propor ações, relação profissional e de trabalho em equipe. Os acadêmicos receberão um conceito a cada trimestre pelo seu desempenho [...]: MUITO BOM, BOM, REGULAR, DEFICIENTE E MUITO DEFICIENTE. Caso o acadêmico atinja o conceito DEFICIENTE ou MUITO DEFICIENTE em mais de um critério avaliado este será desligado do projeto. ${ }^{7}$

Foucault estudou processos de classificação, como os exames. Ele os percebeu dentro de escolas, oficinas, prisões e no exército. Essas avaliações classificatórias podem ser úteis para controlar a ação dos sujeitos "por medidas comparativas que têm a 'norma' como referência" (FOUCAULT, 1987, p.160). A norma marca o que é desejável e normal, enfim, os comportamentos esperados - a norma, ainda, rege internamente o discurso. Uma vez com a norma estabelecida - esta sempre passível de alterações -, um conjunto de técnicas passam a ser mobilizas para levar, o sujeito em direção à norma. Dispositivos e tecnologias de poder, discursivas e não-discursivas, vão encaminhando o sujeito, fazendo-o se mover dentro de uma rota que se acredita dotada de racionalidade.

Apesar de as avaliações utilizarem critérios como "muito bom" e "muito deficiente", deve-se supor que elas não se aplicam de forma neutra. São sujeitos constituídos pelas

${ }^{7}$ Enfatizamos: texto digitado rigorosamente conforme o original; respeitando, inclusive, maiúsculas e minúsculas. 
REGIMES DE SABER/PODER NO DISCURSO SOBRE AVALIAÇÃO DA EXTENSÃO

próprias tramas do poder que avaliam e são avaliados. Sujeitos de poder requerem, também, formas ou possibilidades de liberdade. A liberdade é o que constitui o que Foucault (1987) chamou de resistência. Veiga-Neto (2006, p. 25) compreende que "só há poder se houver alguma chance racional de deslocamento e fuga ou escape". Assim sendo, esse poder que classifica os sujeitos é um meio de controlar as condutas, mas não pode ser considerada uma estratégia de poder que não permite fuga ou o escape.

Ainda segundo Veiga-Neto (2006, p.20), estratégias de poder podem ser entendidas de diferentes formas, caracterizando-se, geralmente, por "uma escolha racional de meios para atingir um fim". Tal fim consideramos ser a formação esperada/idealizada e a conduta tida como ideal para um acadêmico/extensionista: estratégias que visam agir positivamente sobre a conduta do acadêmico, levando-o a enquadrar-se ao "MUITO BOM, BOM, REGULAR" (conforme excerto acima). Sendo a avaliação uma estratégia para alcançar um fim, ela se mostra, nesta analítica, uma estratégia de poder.

Conforme já anunciado acima, não é somente o docente que exerce a avaliação ou a condução dos acadêmicos. O excerto seguinte vai ao encontro disso. O poder avaliador também é exercido pela comunidade:

PE3: Será feita avaliação do desempenho do acadêmico através de relatório elaborado e consulta à comunidade sobre o interesse e continuidade com o trabalho.

Nesse enunciado não é a atividade de Extensão que será avaliada pela comunidade, em termos de interesse pela continuidade ou não. É o acadêmico que será avaliado por esse interesse ou não da comunidade. Consideramos que há uma responsabilização bastante grande do acadêmico: se a comunidade não desejar continuar, seu desempenho será avaliado por isso. Assim sendo, o acadêmico terá de se esforçar para que a comunidade goste da atividade de Extensão, mesmo que, supostamente, possa não necessitar ou ter interesse pela atividade de Extensão prestada. Há, aqui, uma materialidade discursiva que, por sua vez, pode produzir um efeito prático, um efeito no nível da conduta nos acadêmicos. Isso mostra o quanto discurso e prática estão intimamente ligados: o discurso responsabiliza o sujeito e, esse, por sua vez, é impelido seguir uma direção.

A avaliação é, aqui, dividida entre docente e comunidade, afinal, o que está em pauta não é apenas o projeto, mas, principalmente, o desempenho do acadêmico, efetivada por critérios estranhos à sua vontade ou escolha. Tais critérios perpassam, enquanto efeito poder, o docente, a instituição, a comunidade, imprimindo uma força sobre a ação das pessoas, suas 
KRAEMER, C.; CAMPREGHER, J.

escolhas, seu modo de pensar, suas condutas. Poder, para Foucault (1987), também tem essa tônica: atuar sobre a ação de pessoas, agir sobre a conduta do outro, mas também, regular sua própria conduta pelas normalidades instituídas pelo poder.

Vale ressaltar que não há como prever de que forma o sujeito irá se relacionar com essa verdade. Pode tanto tomá-la e se inclinar a ela, quanto pode, também, estabelecer uma postura de contraconduta (FOUCAULT, 2008b) que são sutis formas de resistência. Neste breve artigo estamos, portanto, discutindo o que foi materializado no discurso dos docentes e alguns possíveis efeitos-poder destes discursos nas práticas de Extensão. Porém, prever mecanicamente os resultados seria desacreditar da possibilidade de os sujeitos produzirem contraconduta ou, ainda, intervirem sobre a norma.

Outros dois excertos de PEs, abaixo, mostram que seus proponentes manifestam um discurso ligeiramente modificado sobre a avaliação, inserindo o acadêmico extensionista mais ativamente no processo:

PE12: Participação nas reuniões de trabalho e avaliação com as professoras do Projeto e do Programa de Extensão.

PE5: assiduidade e responsabilidade no cumprimento das ações e nas reuniões da equipe; pontualidade nas atividades; aplicação do conhecimento teórico-prático em situações reais; apresentação dos relatórios; integração com acadêmicos de diferentes cursos na equipe; cumprimento das propostas individuais; desenvolvimento da análise crítica da realidade; integração de conhecimentos em uma proposta interdisciplinar; participação propositiva no planejamento e avaliação das ações; participação em seminários e oficinas; envolvimento em processos científicos e investigativos a partir de metodologias de pesquisa; participação em processos de produção acadêmica e divulgação como artigos científicos, eventos, programas de TV [...] Será emitido um conceito de aproveitamento, classificando as categorias acima em três critérios de desempenho: pontos fortes, evidência moderada e pontos fracos. O desempenho será emitido ao final de cada atividade eventual e após um período de seis meses para as atividades de rotina. Os resultados das avaliações serão discutidos periodicamente com os acadêmicos com o objetivo de aprimorar o seu desempenho (grifos nossos).

O discurso sobre avaliação nesses PEs sinaliza para posições-aluno mais ativas no processo de avaliação. O PE12 fala em avaliação com as professoras do projeto. No PE5 fala em participação na avaliação das ações. Somente nesses dois PEs aparece a avaliação como 


\section{REGIMES DE SABER/PODER NO DISCURSO SOBRE AVALIAÇÃO DA EXTENSÃO}

meio para o acadêmico também avaliar, não só o docente ocupa a posição de avaliador, mas divide com o acadêmico (em parte) tal posição. Nos outros PEs analisados anteriormente o discente ocupa uma posição mais passiva - objeto do poder da avaliação, do acompanhamento e da vigilância.

Este deslocamento do discurso indica um dado relevante da ordem social mais ampla. Enquanto os discursos sobre avaliação dos PEs anteriores está globalmente situado no interior do poder disciplinar, reproduzindo os dispositivos estratégicos próprios a essa modalidade de poder, estes dois últimos PEs analisados se situam numa nova modalidade de poder, própria das sociedades pós-industriais. Nessa nova modalidade de poder ele "sai" de espaços muito fechados (exército, fábrica, escola, etc.) e se exerce em espaços mais abertos, como as redes de colaboração ou mesmo as atuais redes sociais, redes virtuais.

$\mathrm{O}$ fato de serem encontradas as duas modalidades de discurso em formulários do mesmo ano indica que somos uma sociedade que está em transição. Por um lado, estamos ainda fortemente definidos pelo modelo disciplinar de poder, haja vista a maioria dos discursos reproduzirem esta categoria. Por outro lado, uma parcela menor destes discursos sobre avaliação evocam o que Deleuze (2000), discutindo sobre as sociedades estudadas por Foucault, chamou de sociedade de controle "Os confinamentos são moldes, distintas moldagens mas os controles são uma modulação, como uma moldagem auto-deformante que mudasse continuamente, a cada instante [...]" (DELEUZE, 2000, p.221). Segundo o pensamento de Foucault e de Deleuze, nas novas maneiras de se exercer o poder, a vigilância se torna mais difusa, o sujeito do olho que vigia é menos identificável, podendo ser uma câmera, uma senha de cartão de acesso a contas bancárias ou a espaços institucionais.

Como pode ser observado no excerto do PE5, o docente apresenta mecanismos de controle da conduta: assiduidade, responsabilidade, cumprimento de ações, pontualidade, entre outros. Contudo, no PE5, aparecem informações diferenciadas, como análise crítica da realidade. Independentemente de ser crítica ou não, o discurso mostra um docente que se interessa pela análise que o discente possa realizar da realidade. A nós parece emergir nesse excerto a questão da democracia na educação, da descentralização e da autonomia. Não aparece somente a questão do conhecimento do docente (sujeito de conhecimento) que se direciona ao acadêmico (que não tem determinado conhecimento). Há outro processo envolvido que chamaríamos, novamente, de responsabilização dos discentes. Quanto maior responsabilidades divididas entre os sujeitos, mais se estimula o comprometimento. Os resultados são maximizados, tanto nas ações quanto - ou principalmente - no que se produz 
KRAEMER, C.; CAMPREGHER, J.

no corpo do discente: quanto menos necessidade de acompanhamento/avaliação/fiscalização, mais se pode considerar que o sujeito/discente está guiando a si mesmo conforme as normas.

Outro ponto que destacamos do PE5 é a "participação propositiva no planejamento e avaliação das ações". Esse docente elabora uma "posição-acadêmico" mais participativa na avaliação, não somente um sujeito a ser vigiado, acompanhado, descrito em relatórios e avaliado, mas também um colaborador nas ações. Isso não significa ausência de poder, mas modificação no modo de funcionamento do regime de poder.

Os resultados das avaliações, no PE5, serão discutidos; novamente assinalando para uma relação de mão-dupla, mais participativa por parte do discente, ou seja, um poder que funciona mais em rede do que pela distribuição hierárquica. Diz o discurso que os resultados da avaliação serão discutidos no intuito de aprimorar desempenho - fazendo uso das palavras do excerto -, ou seja, há um "fim”, um ideal formativo e um ideal de conduta movendo tal discussão. Mesmo tendo ressaltado o aspecto mais participativo dos discentes, ainda assim, podemos entender que se trata de uma relação de dominação, não exatamente do docente sobre o acadêmico de Extensão, mas de ambos a um regime de poder.

Veiga-Neto $(2006$, p.23) propõe "chamar de dominação a toda e qualquer técnica de governamento de um/uns sobre o(s) outro(s)". Mesmo que não seja somente objeto de avaliação, mas seja também avaliador, no final, a avaliação pretende "aprimorar desempenho" - conforme pode ser observado na última frase do dizer do docente, acima apresentado -, a conduta e o objetivo formativo (os fins) permanecem permeando os meios.

De um jeito ou de outro, o que desejamos destacar nesta seção é que há o governamento ou a governamentalidade atravessando os discursos e as práticas da Extensão. Analisando os excertos de apenas um subitem de um formulário extenso e complexo, percebe-se as modalidades de poder que os atravessam e fixam os modos das relações. São estratégias diferentes, correspondendo a distintos modelos de poder (disciplinar e de controle). Com uma estratégia ou outra, sendo mais em via de mão-única ou dupla, ainda assim, há um conjunto de procedimentos úteis na gestão das condutas.

Não foram os docentes que inventaram os elementos que fazem parte da avaliação, tais como pontualidade, assiduidade, domínio da técnica, entre outros pontos observados nos dizeres dos docentes. Por não terem eles próprios inventado a norma é que hoje é possível avaliar alguém por esses elementos; não poderiam avaliar sujeitos por critérios que já não estivessem estandartizados, que não fossem bem construídos, que não fossem inteligíveis e comungados pelo querer social. Isso permite que tais ações de uns sujeitos sobre os outros sejam mais que compreendidas, sejam aceitas e desejadas. 
REGIMES DE SABER/PODER NO DISCURSO SOBRE AVALIAÇÃO DA EXTENSÃO

Para finalizar, como um dos processos externos de exclusão, não podemos deixar de levar em consideração o contexto de produção das respostas dos docentes ao item. É um contexto, uma circunstância em que ele próprio está sendo avaliado, seu projeto está sendo avaliado - pode ou não ser aprovado pela instituição. Assim sendo, não pode deixar de demonstrar que é capaz de ser um formador de subjetividades, que é capaz de conduzi-las. Sobre ele é que o poder, primeiro, é investido. Situando os excertos neste contexto, fica ainda mais evidente a trama de relações, hierárquicas ou funcionando em rede.

\section{CONSIDERAÇÕES FINAIS}

Este artigo refere-se a um recorte de pesquisa. Procuramos analisar o discurso acerca da avaliação do acadêmico de Extensão. Observamos o imperativo por domínio da técnica (ela deve ser dominada pelo aluno); compreendemos que o lugar de docente, numa instituição dada, ao falar de um processo específico, também regula o dizer (mecanismo externo de regulação); observamos que no discurso aparece um sujeito/aluno descritível, analisável (o que vai ao encontro da regulação ou da racionalidade disciplinar, que separa e individualiza os sujeitos); relações assimétricas que regem a educação também estão presentes no discurso de avaliação do acadêmico de Extensão; observamos a presença da norma, servindo de referência para regular internamente, ou seja, estabelecer os critérios considerados bons para a avaliação do aluno; compreendemos que os critérios de avaliação podem ser uma forma de condução das condutas de si e dos outros; responsabilização dos sujeitos: do que avalia e do avaliado; a leitura dos excertos, desde referenciais arqueológicos e genealógicos, permite compreender os regimes de poder que fazem funcionar as instituições, no interior das tramas sociais.

Respondendo, após essa análise, a pergunta de partida: que mecanismos internos e externos regulam as respostas dadas por professores a um formulário institucional? Como mecanismos inteiros, destacamos na análise: os critérios utilizados na análise, a vigilância hierárquica, a eficiência técnica, o disciplinamento pela norma socialmente produzida, subjetivada e aceita, semelhante ao que ocorre no modelo de educação atual. Como mecanismos externos: a tomada de posições por parte do docente e, ao mesmo tempo, esse também tem seu discurso e sua ação regulada por tal posição assumida (posição docente); a relação assimétrica entre professor aluno; a responsabilização dos sujeitos; o apelo à participação (regime de controle, funcionando em rede); a responsabilidade com os resultados - esses tendo que ser visíveis -; entre outros. 
KRAEMER, C.; CAMPREGHER, J.

A análise arqueológica e genealógica da avaliação mostra, no fundo, o modo de funcionamento dos regimes de saber e de poder que atuam sobre a Extensão e a fazem funcionar no interior de instituições disciplinares e de controle.A avaliação é um processo bastante sutil e quase não percebido ao se falar em Extensão Universitária. Contudo, uma análise mais cuidadosa permite enxergar uma trama complexa de dispositivos estratégicos de poder. No modo como nossa subjetividade moderna é constituída, torna-se difícil pensarmos em processos educativos (ou papéis de professor/aluno) sem pensarmos em processos avaliativos.

\title{
REGIMES OF KNOWLEDGE/POWER IN DISCOURSE ABOUT EVALUATION OF EXTENSION
}

\begin{abstract}
This article discusses the regimes of power/knowledge in actuation in the discourses about evaluation of the University Extension activity. The methodological basis is archeology and genealogy of Foucault. The material analised was extracted in a form where teachers proposed extension projects to be developed in a University of Santa Catarina. These are excerpts from discourse that enable rich analysis of regimes of knowledge/power in actuation in University Extension activity. The main questions is: What are the internal and external mechanisms that regulate the teachers' responses to a institucional form about the evaluation of extension students? The objetive is to analyze the discourse on evaluation of extension students, regimes of knowledge/power that make it possible. What the analysis showed: the place institutional regulates discourse; there is asymmetry between institutional subjects, disciplinary power devices operate on the evaluation, it implies forms of conduction of conduct, the participation concept reflects a change of the disciplinary regime for flexible power called control.
\end{abstract}

Keywords: Disciplinary regime; Control regime; Discourse Analysis;Evaluation of the activity of University Extension

\section{REGIMENES DEL SABER/PODER EN EL DISCURSO SOBRE LA EVALUACIÓN DE LA EXTENSÓN}




\section{Resumen}

Este artículo analiza los regímenes de saber/poder en el discurso de la evaluación de la extensión de la Universidad. La base metodológica es la arqueología y la genealogía de Foucault. El análisis del material fue extraído de un formulario en que los profesores proponen proyectos de extensión, en un Universidad de Santa Catarina. Son extractos del discurso que permiten rica análisis de los regímenes de saber/poder que actuan en la extensión de la Universidad. La pregunta es acerca de que mecanismos internos y externos regulan las respuestas dadas por los profesores en un formulario institucional de extensión acerca de la evaluación académica? Uno tiene que analizar, en el discurso sobre la evaluación de la extensión académica, los regímenes de saber/poder que lo hacen posible. El análisis mostró: el locus institucional regula lo que se habla; existe una asimetría entre los sujetos institucionales; dispositivos de poder disciplinar actúan sobre la evaluación; ella implica formas de conducción de la conducta; el concepto de participación muestra un desplazamiento del régimen disciplinario para el régimen flexible de poder, denominada control.

Palabras clave: Régimen Disciplinarias; Régimen de Control; Análisis del Discurso; Evaluación de Extensión Universitaria

\section{REFERÊNCIAS}

ARROYO, D. M. P. A meta-avaliação e a Extensão Universitária: um estudo de caso. 2010. Dissertação (Mestrado em Educação). Centro de Ciências Humanas e Sociais Aplicadas, Campinas.

BIESTA, G.. Para Além da Aprendizagem. Educação democrática para um futuro humano. Tradução Rosaura Eichenberg. Belo Horizonte: Autêntica Editora, 2013.

BOTOMÉ S. P. Pesquisa Alienada, Ensino Alienante: o equívoco da Extensão Universitária. São Paulo, Vozes: 1996.

COORDENAÇÃO NACIONAL DO FORPROEX. Extensão Universitária: organização e sistematização. Fórum de Pró-Reitores de Extensão das Universidades Públicas Brasileiras. Edison José Corrêa (Org.). Belo Horizonte: Coopmed, 2007.

DELEUZE, G. Conversações. Rio de Janeiro: Ed. 34, 2000. 
KRAEMER, C.; CAMPREGHER, J.

FERNANDES, M. Extensão Universitária: o jogo entre as teorias institucionais e as motivações pessoais. 2008. Dissertação (Mestrado em Educação). Faculdade de Educação e Letras da Universidade Metodista de São Paulo, São Bernardo do Campo.

FÓRUM NACIONAL DE EXTENSÃO E AÇÃO COMUNITÁRIA DAS UNIVERSIDADES E INSTITUIÇÕES DE ENSINO SUPERIOR COMUNITÁRIAS. Contribuições do Forext ao processo institucional da extensão universitária. Bragança Paulista: Editora Universitária São Franciso, 2005.

FOUCAULT, M. Vigiar e Punir: nascimento da prisão. Tradução de Lígia M. Ponde Vassalo. Petrópolis: Vozes, 1987.

História da Sexualidade I. A Vontade de Saber. Rio de Janeiro: Edições Graal, 1988. . As Palavras e As Coisas. São Paulo: Martins Fontes, 1999.

. História da Loucura. São Paulo: Editora Perspectiva, 2000.

. A ordem do discurso. Tradução de Laura Fraga de Almeida Sampaio. 16. ed. São Paulo: Loyola, 2008a.

. Segurança, território, população: curso dado no Collège de France (1977-1978). Tradução Eduardo Brandão; revisão da tradução Claudia Berliner. São Paulo: Martins Fontes, 2008b.

FREIRE, Paulo. Extensão ou Comunicação. Rio de Janeiro: Paz e Terra, 1983.

Pedagogia do Oprimido. 17. ed. Rio de Janeiro: Paz e Terra, 1987.

MENEZES, A.B.N.T. Foucault e as novas tecnologias educacionais: espaços e dispositivos de normalização na sociedade de controle. In. JÚNIOR, D. M. A; VEIGA-NETO, A.; FILHO, A. S. (orgs). Cartografias de Foucault. Belo Horizonte: Autêntica Editora, 2008.

NOGUEIRA, M. D. P. A Extensão Universitária no Brasil: uma revisão conceitual. In: FARIA, D. S. de. Construção Conceitual da Extensão Universitária na América Latina. Brasília: UNB, 2001.

RANCIÈRE, Jacques. O Mestre Ignorante - cinco lições sobre a emancipação intelectual. Tradução: Lílian do Valle. Belo Horizonte: Autêntica, 2002.

SILVA, A. A. S. O Programa UFBA em Campo - ACC: sua contribuição na formação do estudante. 2007. Dissertação (Mestrado em Educação). Faculdade de Educação da Universidade Federal da Bahia, Salvador.

SILVA, R. R. D; FABRIS, E. T. H. O jogo produtivo da educabilidade/governamentalidade na constituição de sujeitos universitários. Revista Brasileira de Educação, Rio de Janeiro: ANPEd; Campinas: Autores Associados, v. 15, n.44, maio/ago. 2010.

SOUSA, A. L. L. A História da Extensão Universitária. Campinas, SP: Ed. Alínea, 2010. 
REGIMES DE SABER/PODER NO DISCURSO SOBRE AVALIAÇÃO DA EXTENSÃO

TOSCANO, G. S. Extensão Universitária e formação cidadã: a UFRN e a UFBA em ação. 2006. Tese (Doutorado em Ciências Sociais). Centro de Ciências Humanas, Letras e Artes da Universidade Federal do Rio Grande do Norte, Natal.

VEIGA-NETO, A. Dominação, violência, poder e educação escolar em tempos de Império. In RAGO, M.; VEIGA-NETO, A. Figuras de Foucault. Belo Horizonte: Autêntica, 2006.

VEIGA-NETO, A.; LOPES, M.C. Inclusão e Governamentalidade. Educação e Sociedade, Campinas: Unicamp, v. 28, n. 100, p. 947-063, out. 2007. http://dx.doi.org/10.1590/S010173302007000300015

VEIGA-NETO, A.; TRAVERSINI, C. Por que Governamentalidade e Educação? Educação e Realidade, Porto Alegre: Universidade Federal do Rio Grande do Sul, v. 34, n.2. Mai/ago 2009.

Data de recebimento: 01/03/2013

Data de aceite: 09/08/2016 